\title{
Comparison of Central Venous Port Procedures Between Puncture vs. Cut-down and Residents vs. Senior Surgeons
}

\author{
RYOTA OTSUBO $^{1}$, HIROSHI YANO ${ }^{1}$, MEGUMI MATSUMOTO ${ }^{1}$, AYA TANAKA ${ }^{1}$, \\ TAKASHI NONAKA ${ }^{1}$, SHIGEKAZU HIDAKA ${ }^{1}$, KEITARO MATSUMOTO ${ }^{1}$, \\ TOMOSHI TSUCHIYA ${ }^{1}$, SHUNTARO SATO $^{2}$ and TAKESHI NAGAYASU ${ }^{1}$ \\ ${ }^{1}$ Department of Surgical Oncology, Nagasaki University Graduate School of Biomedical Sciences, Nagasaki, Japan; \\ ${ }^{2}$ Clinical Research Center, Nagasaki University Hospital, Nagasaki, Japan
}

\begin{abstract}
Background/Aim: To compare operative results between venous puncture $(P)$ with real-time ultrasonography vs. cut-down (CD) with preoperative ultrasonography for totally implantable central vein access device (TICVAD) implantation performed by residents $(R)$ vs. senior surgeons (S). Patients and Methods: Adult oncologic patients $(n=268)$ undergoing TICVAD implantations were retrospectively compared between 172 Ps and 96 CDs. Then, we compared $P$ s performed by $R(P-R, n=131)$ and $S(P-S, n=41)$ and $C D$ s performed by $R(C D-R, n=59)$ and $S(C D-S, n=37)$. Results: Median operation times were $40 \mathrm{~min}$ in the $P$ group and 53.5 min in the $C D$ group, and times were significantly shorter for $P-S$ and $C D-S$. Completion rates were comparable for each method and each surgeon. Intraoperative complication rates were $3.8 \%(P-R), 2.4 \%$ $(P-S)$, and $0 \%(C D-R$ and $C D-S)$. Conclusion: $P$ with realtime ultrasonography did not avoid complications compared to $C D$ with preoperative ultrasonography. The latter performed safely even by residents.
\end{abstract}

Owing to increased adjuvant and neoadjuvant chemotherapy, the necessity of totally implantable central vein access devices (TICVAD) has also increased. These devices are an appropriate option if long-term venous access is indicated, especially to administer cytotoxic agents or intravenous target agents in cancer patients over a long period (1). TICVADs are usually placed via the internal jugular vein or

This article is freely accessible online.

Correspondence to: Ryota Otsubo, MD, Ph.D., Department of Surgical Oncology, Nagasaki University Graduate School of Biomedical Sciences, 1-7-1 Sakamoto, Nagasaki 852-8501, Japan. Tel: +81 958197304, Fax: +81 958197306, e-mail: rotsubo@ nagasakiu.ac.jp

Key Words: Punctures, venous cutdown, implantable catheters, residency, education. subclavian vein with the puncture (P) method, but complications accompanying central venous $\mathrm{P}$, such as hemothorax, pneumothorax, and arterial injury, are critical issues (1-6). Additionally, these complications increase patients' stress and delay treatment with chemotherapy and parenteral nutrition $(7,8)$. Therefore, we previously reported the usefulness of TICVADs with cut-down (CD) of the cephalic vein using preoperative ultrasonography (US) (9). Cephalic vein $\mathrm{CD}$ is not used frequently in clinical practice because of the technical difficulties and the wide-ranging reported incompletion rates $(2.7 \%-20.5 \%)(2,3,10-13)$. Our CD method is associated with fewer complications, short operating time, and higher completion rates compared with conventional $\mathrm{CD}$ without preoperative US or other $\mathrm{P}$ methods (9).

University hospitals must educate many residents, and TICVAD implantation is typically one of the first procedures that residents learn to perform $(14,15)$. Because novice resident surgeons, who are in their first year as surgeons in Japan, often perform TICVAD implantation in our institution, we perform the P method via the internal jugular vein under real-time US guidance, and cephalic vein CD using preoperative US to prevent associated complications. However, it is still unclear whether these approaches are suitable for novice surgeons, and little evidence is available regarding differences between novice and experienced surgeons performing these procedures (14-16). The present study aimed to compare the operative results between the $\mathrm{P}$ and CD methods, and between residents and senior surgeons, regarding TICVAD implantation.

\section{Patients and Methods}

The ethics committee of our institution approved this study and the use of the details in the patients' medical records for the study (20061519). The study met the guidelines of the Declaration of Helsinki. We retrospectively reviewed the records of 296 oncologic patients undergoing TICVAD implantation from April 2014 to December 2019 in the Department of Surgical Oncology at Nagasaki 


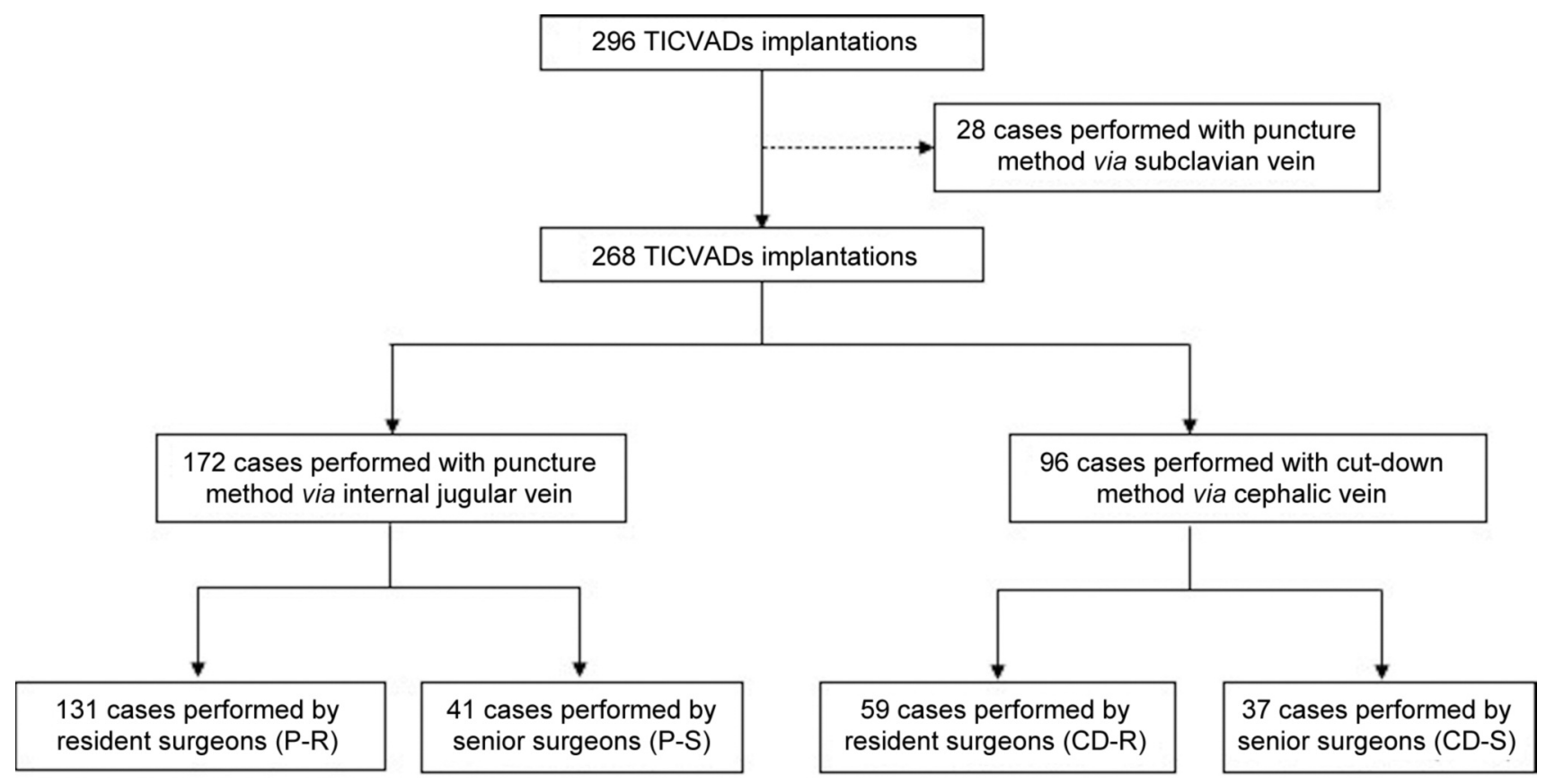

Figure 1. Flow chart of all cases. TICVADs: Totally implantable central venous access devices; P-R: Puncture method performed by resident surgeons; P-S: puncture method performed by senior surgeons; CD-R: cut-down method performed by resident surgeons; CD-S: cut-down method performed by senior surgeons.

University Hospital. Because we excluded 28 patients in whom TICVAD implantations were performed by the P method via the subclavian vein, 268 oncologic patients were eligible for this study. All puncture sites for the $\mathrm{P}$ method were jugular veins, and all procedures for the $\mathrm{P}$ method were performed under real-time intraoperative US. The study group comprised 98 men and 170 women, with a median age of 64 years. The main primary diagnosis was digestive system cancer $(n=92)$, followed by haematological malignancy $(n=63)$, breast cancer $(n=57)$, gynaecological cancers $(n=20)$, lung cancer $(n=19)$, and other tumours $(n=17)$. A single preoperative dose of a first-generation cephalosporin was administrated in patients not receiving antibiotics. Four types of TICVADs were used: 169 (63.1\%) were Safe Guide ${ }^{\text {TM }}$ MicroNeedle ports with a closed-end 8.0-Fr single lumen (Cardinal Health, Dublin, OH, USA), 78 (29.1\%) were PowerPort devices with a closed-end 8.0-Fr single lumen (Bard Access Systems, Salt Lake City, UT, USA), 13 (4.9\%) were P-U Celsite ports with an open-end 6.0-Fr single lumen (Toray Medical Co., Ltd. Tokyo, Japan), and 8 (3.0\%) were PowerPort Slims with an open-end 6.0-Fr single lumen (Bard Access Systems). The position of the distal tip of the catheter in the superior vena cava was confirmed in all patients using intraoperative fluoroscopic guidance to identify the tracheal bifurcation.

We divided patients into two groups based on the operating procedures: $\mathrm{P}$ method (172 procedures performed by 51 surgeons) and CD method ( 96 procedures performed by 21 surgeons). We also divided the patients into two additional subgroups on the basis of the surgeons' experience for both the $\mathrm{P}$ and $\mathrm{CD}$ methods, as follows: $\mathrm{P}$ method performed by resident surgeons ( $\mathrm{P}-\mathrm{R}, 131$ procedures performed by 32 resident surgeons), $\mathrm{P}$ method performed by senior surgeons (P-S, 41 procedures performed by 19 senior surgeons), CD method performed by resident surgeons (CD-R, 59 procedures performed by 15 resident surgeons), and CD method performed by senior surgeons (CD-S, 37 procedures performed by 6 senior surgeons) (Figure 1). None of the resident surgeons were boardcertified surgeons, at 3 years after graduation from medical school, whereas all senior surgeons were board-certified. We compared operation time, including changing the $\mathrm{P}$ site and changing the procedure from $\mathrm{CD}$ to $\mathrm{P}$, completion rate, complications, and preoperative US findings (vein diameter, depth, and convergence between the cephalic vein and axillary vein). Complications were divided into intraoperative and postoperative complications.

Percutaneous puncture procedure $(P-R$ and $P-S)$. All puncture sites were the internal jugular veins, and real-time intraoperative US visualized the needle as it was guided through the skin and into the vein. Successful $\mathrm{P}$ was confirmed by venous return in the syringe. The Seldinger technique was used with a guide wire, a dilator, and a peel-away sheath for catheter insertion, and fluoroscopy was used to confirm the position of the tip of the catheter in the superior vena cava. Two incisions were necessary: a small neck incision at the catheter exit site from the skin and a second larger incision to implant the reservoir on the chest wall. A subcutaneous tunnel was made from the larger incision to the small incision in front of the clavicle, and the catheter was passed from the small incision in the neck to the larger incision in the chest wall. Next, the catheter was connected to the reservoir and placed on the major pectoral fascia. Fixation between the reservoir and the major pectoral fascia was not usually performed with the P method. Postoperative X-ray examination was performed to rule out pneumothorax and catheter kinks.

Cephalic vein cut-down procedure $(C D-R$ and $C D-S)$. Primary approach. Generally, when resident surgeons performed the CD 

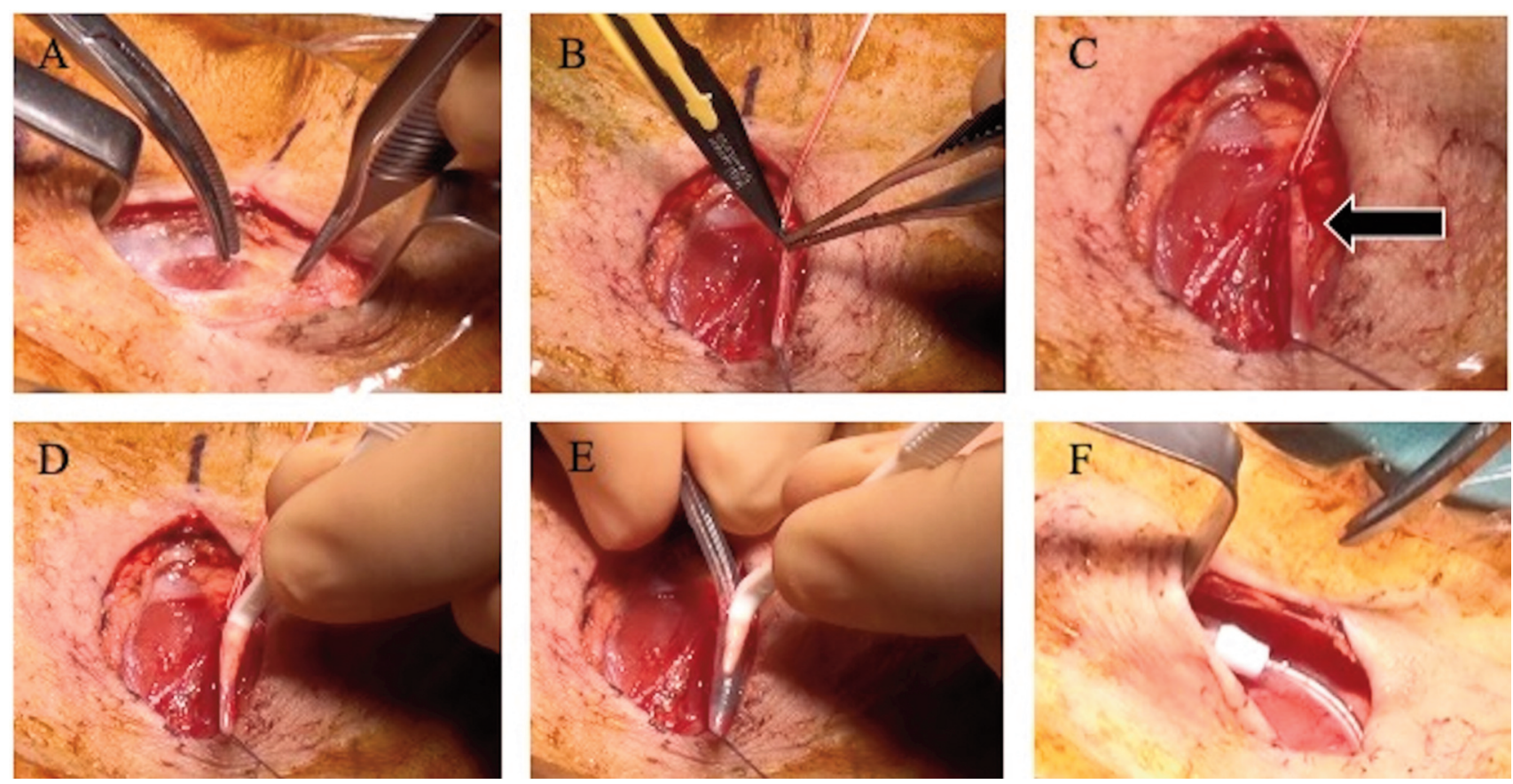

Figure 2. Intraoperative images showing the cut-down approach in the right cephalic vein. A) The deltopectoral groove was exfoliated. B) The cephalic vein was encircled and cut. C) Small venotomy of the cephalic vein (arrow). D) The vein pick was inserted into the cephalic vein. E) The catheter was inserted using the vein pick. F) The connected reservoir was implanted on the major pectoral muscle.

procedure, a senior surgeon helped as the first assistant surgeon. After sterilizing the patient's skin, the skin and subcutaneous layer were incised for approximately $4 \mathrm{~cm}$ in the upper anterior chest wall along the deltopectoral groove. The fascia between the deltoid and major pectoral muscle was cut along the muscles, and the cephalic vein was exposed then ligated distally and encircled cranially with 3-0 absorbable suture. The cephalic vein was transected, and the catheter was then inserted directly into the cephalic vein through a transverse venotomy with a vein pick. We used fluoroscopy to confirm the position of the tip of the catheter in the superior vena cava. Using the same incision, we created a subcutaneous pocket on the major pectoral fascia, and connected the catheter to the reservoir. Patency for blood retrieval and no leakage at infusion were verified by direct puncture with a Huber needle, and the reservoir was sutured to the major pectoral fascia with two absorbable sutures (Figure 2). Postoperative X-ray examination was performed to confirm the location of the catheter and reservoir.

Secondary approach. If the cephalic vein was not identified, was too small to perform $\mathrm{CD}$, the catheter could not be advanced into the superior vena cava, or other reasons prevented the primary approach, the Seldinger technique was performed in the ipsilateral internal jugular vein using real-time intraoperative US. Venous access was performed using the same procedure as for P-R and P$\mathrm{S}$, and the reservoir was placed using the incision for the cephalic vein $\mathrm{CD}$ approach and sutured to the major pectoral fascia as for the primary approach.

Preoperative ultrasonography. When the $\mathrm{CD}$ approach was attempted, preoperative US was performed with an $8.0-\mathrm{MHz}$ frequency linear probe (Viamo, Toshiba Medical System, Tochigi,
Japan). The cephalic vein is located in the fat below the fascia between the deltoid and the major pectoral muscle. We evaluated the cephalic vein transverse diameter and depth near the coracoid process of the scapula, and venous convergence between the cephalic and axillary vein by searching upward, to improve the completion rate (9).

Statistical analysis. We first compared data between the P and CD methods and then compared data between residents and senior surgeons for each method. Continuous data and categorical data are expressed as medians with ranges and as cases with percentages, respectively. The statistical program JMP 14 (SAS Institute, Inc., Cary, NC, USA) was used to analyze the data. Continuous data were compared using the Wilcoxon signed-rank test, and categorical data were compared using the $\chi^{2}$ test or Fisher's exact test, when appropriate. Probability values $<0.05$ were considered statistically significant for all tests.

\section{Results}

The demographic data for each group are summarized in Table I. The median age for the CD method was significantly younger than that for the $\mathrm{P}$ method. Patients with digestive disease were most common in the P-R and P-S groups because the senior surgeons on the digestive disease team in our department preferred the P method, whereas patients with breast cancer predominated in the CD-R and CD-S groups because the senior surgeons on the breast and 
Table I. Comparison of patients' characteristics in the four groups undergoing TICVAD implantation.

\begin{tabular}{|c|c|c|c|c|c|c|c|}
\hline & \multicolumn{2}{|c|}{ Puncture (n=172) } & \multirow[b]{2}{*}{$p$-Value } & \multicolumn{2}{|c|}{ Cut-down (n=96) } & \multirow[b]{2}{*}{$p$-Value } & \multirow[t]{2}{*}{$p$-Value } \\
\hline & $\begin{array}{l}\text { Resident; P-R } \\
\quad(\mathrm{n}=131)\end{array}$ & $\begin{array}{l}\text { Senior; P-S } \\
\quad(n=41)\end{array}$ & & $\begin{array}{l}\text { Resident; CD-R } \\
\quad(\mathrm{n}=59)\end{array}$ & $\begin{array}{l}\text { Senior; CD-S } \\
\quad(n=37)\end{array}$ & & \\
\hline \multirow[t]{2}{*}{ Male/Female } & \multicolumn{2}{|c|}{$78 / 94$} & & \multicolumn{2}{|c|}{$20 / 76$} & & $<0.001^{*}$ \\
\hline & $61 / 70$ & $17 / 24$ & 0.595 & $18 / 41$ & $2 / 35$ & 0.004 & \\
\hline \multirow[t]{2}{*}{ Age } & \multicolumn{2}{|c|}{$66.5(24-83)$} & & \multicolumn{2}{|c|}{$59.0(19-87)$} & & \multirow[t]{2}{*}{$<0.001^{*}$} \\
\hline & $67(24-83)$ & $65(34-83)$ & 0.646 & $62(19-87)$ & $54.5(29-79)$ & $0.028 *$ & \\
\hline \multirow[t]{2}{*}{ Body Mass Index } & \multicolumn{2}{|c|}{$21.2(12.3-33.3)$} & & \multicolumn{2}{|c|}{$20.8(13.9-37.0)$} & & \multirow[t]{2}{*}{0.550} \\
\hline & $21.3(12.9-33.3)$ & $20.8(12.3-31.9)$ & 0.612 & $21.4(16.9-37.0)$ & $20.4(13.9-32.9)$ & 0.436 & \\
\hline \multicolumn{8}{|l|}{ Malignancy type } \\
\hline \multirow{2}{*}{ Digestive, n (\%) } & \multicolumn{2}{|c|}{$81(47.1 \%)$} & & \multicolumn{2}{|c|}{$11(11.5 \%)$} & & \multirow{2}{*}{$<0.001^{*}$} \\
\hline & $58(44.3 \%)$ & $23(56.1 \%)$ & 0.212 & $11(18.6 \%)$ & $0(\%)$ & 0.006 & \\
\hline \multirow[t]{2}{*}{ Hematologic, n (\%) } & \multicolumn{2}{|c|}{$41(23.8 \%)$} & & \multicolumn{2}{|c|}{$22(22.9 \%)$} & & \multirow[t]{2}{*}{1.000} \\
\hline & $36(27.5 \%)$ & $5(12.2 \%)$ & 0.058 & $17(28.8 \%)$ & $5(13.5 \%)$ & 0.133 & \\
\hline \multirow[t]{2}{*}{ Breast, n (\%) } & \multicolumn{2}{|c|}{$13(7.6 \%)$} & & \multicolumn{2}{|c|}{$44(45.8 \%)$} & & \multirow[t]{2}{*}{$<0.001^{*}$} \\
\hline & $5(3.8 \%)$ & $8(19.5 \%)$ & $<0.001$ & $16(27.1 \%)$ & $28(75.7 \%)$ & $<0.001 *$ & \\
\hline \multirow[t]{2}{*}{ Gynecologic, n (\%) } & \multicolumn{2}{|c|}{$14(8.1 \%)$} & & \multicolumn{2}{|c|}{$6(6.3 \%)$} & & \multirow[t]{2}{*}{0.636} \\
\hline & $12(9.2 \%)$ & $2(4.9 \%)$ & 0.523 & $4(6.8 \%)$ & $2(5.4 \%)$ & 1.000 & \\
\hline \multirow[t]{2}{*}{ Lung, n (\%) } & \multicolumn{2}{|c|}{$17(9.9 \%)$} & & & & & 0.023 \\
\hline & $15(11.5 \%)$ & $2(4.9 \%)$ & 0.367 & $1(1.7 \%)$ & $1(2.7 \%)$ & 1.000 & \\
\hline Others, n (\%) & $6(3$ & & & 11( & $5 \%)$ & & $0.017^{*}$ \\
\hline & $5(3.8 \%)$ & $1(2.4 \%)$ & 1.000 & $10(17.0 \%)$ & $1(2.7 \%)$ & 0.046 & \\
\hline
\end{tabular}

TICVAD: Totally implantable central vein access device. *Statistically significant.

endocrine teams in our department preferred the CD method. Operation data are summarized in Table II. The median operation times were $40 \mathrm{~min}$ (range $=21-122 \mathrm{~min}$ ) for the $\mathrm{P}$ method and $53.5 \mathrm{~min}$ (range=28-88 $\mathrm{min}$ ) for the CD method. For the $\mathrm{P}$ method, the median operation times were $42 \mathrm{~min}$ (range $=21-122 \mathrm{~min}$ ) in the P-R group and $33 \mathrm{~min}$ (range=23$82 \mathrm{~min}$ ) in the P-S group. For the CD method, the median operation times were $57.5 \mathrm{~min}$ (range $=33-88 \mathrm{~min}$ ) in the CD$\mathrm{R}$ group and $48 \mathrm{~min}$ (range=28-68 min) in the CD-S group. The operation time for the CD method was significantly longer than for the $\mathrm{P}$ method, and the operation times in the $\mathrm{P}-\mathrm{S}$ and CD-S groups were significantly shorter than in the P-R and CD-R groups $(p<0.001)$. Completion rates for the primary approach were $93.6 \%$ for the P method and $92.7 \%$ for the $\mathrm{CD}$ method. Completion rates for the primary approach were $93.1 \%$ in the P-R group and $95.1 \%$ in the P$\mathrm{S}$ group, with no significant difference between the subgroups for the $\mathrm{P}$ method. Completion rates for the primary approach were $91.5 \%$ in the CD-R group and $94.6 \%$ in the CD-S group, with no significant difference between the subgroups for the $\mathrm{CD}$ method. Lack of success with the $\mathrm{P}$ method was related to puncture failure $(\mathrm{n}=6)$, arterial puncture $(n=3)$, and failure to advance the catheter into the central vein $(n=2)$, with no significant difference between the subgroups for the P method. Lack of success with the CD method was related to failure to advance the catheter into the central vein $(n=3)$ and failure to cannulate the catheter into the cephalic vein $(n=4)$, with no significant difference between the subgroups for the CD method.

Eighty-nine implantations were successful, and seven failed using the CD method. The venous diameter $(p=0.005)$ and venous convergence $(p=0.013)$ significantly affected the rate of successful implantation, after univariate analysis. Multivariate logistic regression analysis was not performed because there were too few failed cases (Table III). Adopting $3.0 \mathrm{~mm}$ as a cut-off value for the venous diameter in the preoperative US, the completion rate during the primary approach with venous diameters $>3.0 \mathrm{~mm}$ was $100 \%$ $(64 / 64)$, whereas the completion rate with diameters $\leq 3.0$ mm was $81.3 \%(26 / 32)$.

Seven intraoperative complications were observed for the $\mathrm{P}$ method, namely, six arterial punctures $(3.5 \%)$ and one pneumothorax $(0.6 \%)$. One arterial puncture $(2.4 \%)$ occurred in the P-S group. There were no intraoperative complications for the CD method. Regarding postoperative complications, there were 22 postoperative complications for the $\mathrm{P}$ method, namely, 9 infections (5.2\%), 2 catheter breakages (1.2\%), 1 catheter obstruction $(0.6 \%)$, and 2 cases of the reservoir twisting secondary to rotation $(1.2 \%)$. There were two postoperative complications in the $\mathrm{P}-\mathrm{S}$ group, namely, one infection $(2.4 \%)$ and one thrombus $(2.4 \%)$. There was no significant difference between the subgroups for the $\mathrm{P}$ 
Table II. Operation data for the four groups of patients undergoing TICVAD implantation.

\begin{tabular}{|c|c|c|c|c|c|c|c|}
\hline & \multicolumn{2}{|c|}{ Puncture $(\mathrm{n}=172)$} & \multirow[b]{2}{*}{$p$-Value } & \multicolumn{2}{|c|}{ Cut-down $(\mathrm{n}=96)$} & \multirow[b]{2}{*}{$p$-Value } & \multirow[t]{2}{*}{$p$-Value } \\
\hline & $\begin{array}{l}\text { Resident; P-R } \\
\quad(\mathrm{n}=131)\end{array}$ & $\begin{array}{l}\text { Senior; P-S } \\
\quad(\mathrm{n}=41)\end{array}$ & & $\begin{array}{l}\text { Resident; CD-R } \\
\quad(\mathrm{n}=59)\end{array}$ & $\begin{array}{l}\text { Senior; CD-S } \\
\quad(n=37)\end{array}$ & & \\
\hline Number of & \multicolumn{2}{|c|}{$51 / 172$} & & \multicolumn{2}{|c|}{$21 / 96$} & & 0.330 \\
\hline surgeons/operations & $32 / 131$ & $19 / 41$ & 0.072 & $15 / 59$ & $6 / 37$ & 0.461 & \\
\hline Operation time (minutes) & \multicolumn{2}{|c|}{$40(21-122)$} & & \multicolumn{2}{|c|}{$53.5(28-88)$} & & $<0.001 *$ \\
\hline & $42(21-122)$ & $33(23-82)$ & $<0.001^{*}$ & $57.5(33-88)$ & $48(28-68)$ & $<0.001 *$ & \\
\hline $\begin{array}{l}\text { Completion rate at the } \\
\text { primary approach }(\%)\end{array}$ & \multicolumn{2}{|c|}{$93.6 \%$} & 1.000 & \multicolumn{2}{|c|}{$92.7 \%$} & 0.703 & 0.802 \\
\hline \multicolumn{8}{|l|}{$\begin{array}{l}\text { The reason of } \\
\text { unsuccessfulness, n (\%) }\end{array}$} \\
\hline Failure of puncture & \multicolumn{2}{|c|}{$6(3.5 \%)$} & & \multicolumn{2}{|c|}{0} & & \multirow[t]{2}{*}{0.091} \\
\hline \multirow{3}{*}{ Arterial puncture } & $5(3.8 \%)$ & $1(2.4 \%)$ & 1.000 & 0 & 0 & 1.000 & \\
\hline & \multicolumn{2}{|c|}{$3(1.7 \%)$} & & \multicolumn{2}{|c|}{0} & & \multirow[t]{2}{*}{0.555} \\
\hline & $2(1.5 \%)$ & $1(2.4 \%)$ & 0.561 & 0 & 0 & 1.000 & \\
\hline \multirow[t]{2}{*}{ Failure to advance } & \multicolumn{2}{|c|}{$2(1.2 \%)$} & \multicolumn{4}{|c|}{$3(3.1 \%)$} & \multirow[t]{2}{*}{0.353} \\
\hline & $2(1.5 \%)$ & 0 & 1.000 & $2(3.4 \%)$ & $1(2.7 \%)$ & 1.000 & \\
\hline \multirow[t]{2}{*}{ Failure of cannulation } & \multicolumn{2}{|c|}{0} & \multicolumn{4}{|c|}{$4(4.2 \%)$} & $0.016^{*}$ \\
\hline & 0 & 0 & 1.000 & $3(5.1 \%)$ & $1(2.7 \%)$ & 1.000 & \\
\hline
\end{tabular}

TICVAD: Totally implantable central vein access device. *Statistically significant.

method regarding intraoperative and postoperative complications. There were six postoperative complications for the CD method, namely, three infections $(3.1 \%)$ and three twisted reservoirs $(3.1 \%)$. There was no significant difference between the subgroups for the CD method regarding intraoperative and postoperative complications. There was also no significant difference between the methods regarding the total complications (Table IV).

\section{Discussion}

In this study, we performed 268 TICVAD implantations, and we retrospectively divided patients into two groups based on the implantation method and subsequently divided each group into two subgroups on the basis of the surgical experience of the operators. To avoid major complications and improve the completion rate, we performed the $\mathrm{P}$ method using real-time US and the CD method using preoperative US (9). Although the operation time in the CD-R group was significantly longer compared with the other groups, there was no difference in the intraoperative and postoperative complication rates between the CD-R and CD-S groups. Regarding the completion rate, there was no significant difference between the $\mathrm{CD}$ and $\mathrm{P}$ method. Larger venous diameter, especially diameters $>3.0 \mathrm{~mm}$, and venous convergence confirmed with preoperative US contributed to successful procedures using the $\mathrm{CD}$ method. Although five arterial punctures and one pneumothorax occurred in the P$\mathrm{R}$ group, and one arterial puncture occurred in the P-S group,
Table III. Comparison of the variables between successful and failed TICVAD implantations in the CD group.

\begin{tabular}{lccc}
\hline Variables & $\begin{array}{c}\text { Successful } \\
\text { implantation } \\
(\mathrm{n}=89)\end{array}$ & $\begin{array}{c}\text { Failed } \\
\text { implantation } \\
(\mathrm{n}=7)\end{array}$ & $p$-Value \\
\hline $\begin{array}{l}\text { Gender } \\
\text { (Male/Female) }\end{array}$ & $19 / 70$ & $1 / 6$ & 1.000 \\
$\begin{array}{l}\text { Age } \\
\text { BMI }\end{array}$ & $60(19-87)$ & $44(42-74)$ & 0.285 \\
$\begin{array}{l}\text { Resident/Senior } \\
\text { surgeons }\end{array}$ & $21.4(13.9-37.0)$ & $20.2(17.9-22.8)$ & 0.403 \\
$\begin{array}{l}\text { Types of TICVADs } \\
\text { PowerPort/MicroNeedle/ }\end{array}$ & $43 / 35$ & $5 / 2$ & 0.703 \\
$\begin{array}{l}\text { P-U Celsite/ } \\
\text { PowerPort Slim }\end{array}$ & & & \\
$\begin{array}{l}\text { Venous diameter (mm) } \\
\text { Venous depth (mm) }\end{array}$ & $3.5(1.4-5.2)$ & $2.95(2.2-3.0)$ & $0.005^{*}$ \\
$\begin{array}{l}\text { Venous convergence } \\
\text { (Yes/No) }\end{array}$ & $11.0(3.0-22.0)$ & $13.9(13.3-18.0)$ & 0.105 \\
\hline
\end{tabular}

TICVAD: Totally implantable central vein access device; CD: cut-down. *Statistically significant.

even with intraoperative US, there were no intraoperative fatal complications in the CD-R and CD-S groups.

In a previous retrospective study, $\mathrm{CD}$ procedures for TICVAD using preoperative US were compared between procedures performed by resident surgeons 3-5 years after graduation without board certification and senior surgeons with board certification (15). Operation time and the 
Table IV. Intraoperative and postoperative complications in the four groups of patients undergoing TICVAD implantation.

\begin{tabular}{|c|c|c|c|c|c|c|c|}
\hline & \multicolumn{2}{|c|}{ Puncture $(n=172)$} & \multirow[b]{2}{*}{$p$-Value } & \multicolumn{2}{|c|}{ Cut-down (n=96) } & \multirow[b]{2}{*}{$p$-Value } & \multirow[t]{2}{*}{$p$-Value } \\
\hline & $\begin{array}{c}\text { Resident; P-R } \\
\quad(\mathrm{n}=131)\end{array}$ & $\begin{array}{l}\text { Senior; P-S } \\
\quad(n=41)\end{array}$ & & $\begin{array}{l}\text { Resident; CD-R } \\
\quad(\mathrm{n}=59)\end{array}$ & $\begin{array}{l}\text { Senior; CD-S } \\
\quad(\mathrm{n}=37)\end{array}$ & & \\
\hline \multicolumn{8}{|l|}{ Intraoperative complications } \\
\hline \multirow[t]{2}{*}{ Arterial puncture, n (\%) } & \multicolumn{2}{|c|}{$6(3.5)$} & & \multicolumn{2}{|c|}{0} & & \multirow[t]{2}{*}{0.091} \\
\hline & $5(3.8)$ & $1(2.4)$ & 1.000 & 0 & 0 & 1.000 & \\
\hline \multirow[t]{2}{*}{ Pneumothorax, n, (\%) } & \multicolumn{2}{|c|}{$1(0.6)$} & & \multicolumn{2}{|c|}{0} & & \multirow[t]{2}{*}{1.000} \\
\hline & $1(0.8)$ & 0 & 1.000 & 0 & 0 & 1.000 & \\
\hline $\begin{array}{l}\text { Subtotal of intraoperative } \\
\text { complications, } \mathrm{n}(\%)\end{array}$ & \multicolumn{2}{|c|}{$7(4.1)$} & 1.000 & \multirow{2}{*}{\multicolumn{2}{|c|}{0}} & 1.000 & 0.052 \\
\hline \multicolumn{6}{|c|}{ Postoperative complications } & & \\
\hline \multirow[t]{2}{*}{ Infection, $\mathrm{n}(\%)$} & \multicolumn{2}{|c|}{$9(5.2)$} & & \multicolumn{2}{|c|}{$3(3.1)$} & & \multirow[t]{2}{*}{0.547} \\
\hline & $8(6.1)$ & $1(2.4)$ & 0.688 & $2(3.4)$ & $1(2.7)$ & 1.000 & \\
\hline \multirow[t]{2}{*}{ Catheter breakage, n (\%) } & \multicolumn{2}{|c|}{$2(1.2)$} & & \multicolumn{2}{|c|}{0} & & \multirow[t]{2}{*}{0.539} \\
\hline & $2(1.5)$ & 0 & 1.000 & 0 & 0 & 1.000 & \\
\hline \multirow[t]{2}{*}{ Catheter obstruction, $\mathrm{n}(\%)$} & \multicolumn{2}{|c|}{$1(0.6)$} & & \multicolumn{2}{|c|}{0} & & \multirow[t]{2}{*}{1.000} \\
\hline & $1(0.8)$ & 0 & 1.000 & 0 & 0 & 1.000 & \\
\hline \multirow[t]{2}{*}{ Thrombus, n (\%) } & \multicolumn{2}{|c|}{$1(0.6)$} & & \multicolumn{2}{|c|}{0} & & 1.000 \\
\hline & 0 & $1(2.4)$ & 1.000 & 0 & 0 & 1.000 & \\
\hline Reservoir twisting, n (\%) & & & & & & & 0.353 \\
\hline & $2(1.5)$ & 0 & 1.000 & $1(1.7)$ & $2(5.4)$ & 0.557 & \\
\hline Subtotal of postoperative & & & & & & & 0.636 \\
\hline complications, n (\%) & $13(9.9)$ & $2(4.9)$ & 0.526 & $3(5.1)$ & $3(8.1)$ & 0.673 & \\
\hline Total, n (\%) & & & & & & & 0.101 \\
\hline & $19(14.5)$ & $3(7.3)$ & 0.292 & $3(5.1)$ & $3(8.1)$ & 0.673 & \\
\hline
\end{tabular}

TICVAD: Totally implantable central vein access device.

complication rate were equivalent between the resident and senior surgeons. Moreover, the completion rate was significantly higher in the resident surgeon group, and preoperative US enabled avoiding a patient's difficult side and contributed to a high completion rate. We also used preoperative US to evaluate whether the cephalic vein was suitable for $\mathrm{CD}$, especially regarding venous convergence between the cephalic and axillary vein, which also contributed to the high completion rate for $\mathrm{CD}$ and relieved stress for both patients and surgeons.

Pneumothorax and haemothorax after TICVAD implantation, reported at a rate of $0.5 \%-6 \%(5,6)$, are typical complications secondary to incorrect venous puncture. In our study, CD was associated with a much lower risk of these major complications. We encountered no intraoperative complications in the $\mathrm{CD}-\mathrm{R}$ group because all $\mathrm{CD}$ procedures were performed with the assistance of a senior surgeon. Other studies have also reported no significant difference in intraoperative and postoperative complication rates when comparing TICVAD implantations performed by residents with the help of attending surgeons, with approximately $80 \%$ of TICVAD implantations performed using the CD method (16). In our institution, we require complete skeletonization of the cephalic vein during the $\mathrm{CD}$ procedure (Figure 2) performed by resident surgeons, to ensure venotomy and catheter insertion, and we consider that the CD procedure is a good opportunity for resident surgeons to learn basic surgical skills. However, CD performed by our resident surgeons required a longer operation time compared with senior surgeons performing either $\mathrm{CD}$ or $\mathrm{P}$ procedures. A prospective randomized trial (PORTAS-3-Trial) compared 583 patients undergoing TICVAD implantation using the CD method vs. 576 patients using the P method. The trial showed that the rate of critical complications, such as pneumothorax and haemothorax, was significantly lower with the CD method, and operation time was also shorter for the P method. Primary success rates, tolerability, morbidity, radiation dose, and 30-day mortality did not differ significantly between CD and $\mathrm{P}$ methods (17). Therefore, CD should be included in the reference standard for TICVAD implantation.

In this study, five patients developed a twisted reservoir as a postoperative complication: one patient $(1.7 \%)$ in the CD-R group and two patients $(5.4 \%)$ in the CD-S group; therefore, rates were higher than with the $\mathrm{P}$ method. Twisting is more likely if the reservoir is not sutured to the fascia (18). However, our conventional CD procedure involves placing two absorbable sutures in the fascia, which requires more subcutaneous space to suture firmly. Because we suspected that an excessively large subcutaneous pocket for suturing to the fascia may have led to reservoir twisting in 
the subcutaneous pocket, we now create a narrower, $2-\mathrm{cm}$ width subcutaneous pocket, to prevent reservoir twisting without suturing to the fascia.

The first limitation of this study is its retrospective design, which meant that selection bias related to patients' backgrounds and the type of procedure could not be eliminated. The second limitation of this study is the small overall sample size and the different sample sizes in the four groups, especially in the P-S and CD-S groups, which was related to the fact that senior surgeons rarely perform TICVAD implantations, in our institution.

In conclusion, the $\mathrm{P}$ method did not prevent related complications when performed by resident vs. senior surgeons using real-time US guidance; however, the CD method was performed safely even by resident surgeons because the procedure is performed under the direct supervision of the assistant senior surgeon. In addition, we improved the completion rate by confirming sufficient venous diameter and convergence between the cephalic and axillary veins, using preoperative US.

\section{Conflicts of Interest}

The Authors have no conflicts of interest to declare in relation to this study.

\section{Authors' Contributions}

RO and TN were responsible for the study concept. SS was responsible for statistical analysis. All authors except for SS collaborated in the patients' medical procedure. All Authors approved the final manuscript for submission and agreed to be accountable for the work.

\section{Acknowledgements}

The Authors thank Jane Charbonneau, DVM, from Edanz Group (https://en-author-services.edanz.com/ac) for editing a draft of this manuscript.

\section{References}

1 Kock HJ, Pietsch M, Krause U, Wilke H and Eigler FW: Implantable vascular access systems: experience in 1500 patients with totally implanted central venous port systems. World J Surg 22(10): 12-16, 1998. PMID: 9465755.

2 Biffi R, Orsi F, Pozzi S, Pace U, Bonomo G, Monfardini L, Della Vigna P, Rotmensz N, Radice D, Zampino MG, Fazio N, de Braud F, Andreoni B and Goldhirsch A: Best choice of central venous insertion site for the prevention of catheter-related complications in adult patients who need cancer therapy: a randomized trial. Ann Oncol 20(5): 935-940, 2009. PMID: 19179550. DOI: $10.1093 /$ annonc/mdn701

3 Granziera E, Scarpa M, Ciccarese A, Filip B, Cagol M, Manfredi V, Alfieri R, Celentano C, Cappellato S, Castoro C and Meroni M: Totally implantable venous access devices: Retrospective analysis of different insertion techniques and predictors of complications in 796 devices implanted in a single institution. BMC Surg 14: 27, 2014. PMID: 24886342. DOI: 10.1186/14712482-14-27

4 Klaiber U, Grummich K, Jensen K, Saure D, Contin P, Hüttner FJ, Diener MK and Knebel P: Closed cannulation of subclavian vein $v s$. open cut-down of cephalic vein for totally implantable venous access port (TIVAP) implantation: Protocol for a systematic review and proportional meta-analysis of perioperative and postoperative complications. Syst Rev 4: 53, 2015. PMID: 25896394. DOI: 10.1186/s13643-015-0043-1

5 Shiono M, Takahashi S, Takahashi M, Yamaguchi T and Ishioka C: Current situation regarding central venous port implantation procedures and complications: a questionnaire-based survey of 11,693 implantations in Japan. Int J Clin Oncol 21(6): 1172-1182, 2016. PMID: 27324107. DOI: 10.1007/s10147-016-1003-z

6 Orci LA, Meier RPH, Morel P, Staszewicz W and Toso C: Systematic review and meta-analysis of percutaneous subclavian vein puncture versus surgical venous cutdown for the insertion of a totally implantable venous access device. Br J Surg 101(2): 8-16, 2014. PMID: 24276950. DOI: 10.1002/bjs.9276

7 Kakkos A, Bresson L, Hudry D, Cousin S, Lervat C, Bogart E, Meurant JP, El Bedoui S, Decanter G, Hannebicque K, Regis C, Hamdani A, Penel N, Tresch-Bruneel E and Narducci F: Complication-related removal of totally implantable venous access port systems: Does the interval between placement and first use and the neutropenia-inducing potential of chemotherapy regimens influence their incidence? A four-year prospective study of 4045 patients. Eur J Surg Oncol 43(4): 689-695, 2017. PMID: 27889197. DOI: 10.1016/j.ejso.2016.10.020

8 Tsutsumi S, Fukasawa T, Fujii T, Tabe Y, Kigure W, Asao T and Kuwano H: Central venous port system-related complications in outpatient chemotherapy for colorectal cancer. Hepatogastroenterology 59(116): 1079-1080, 2012. PMID: 22580658. DOI: $10.5754 /$ hge09283

9 Otsubo R, Hatachi T, Shibata K, Yoshida T, Watanabe H, Oikawa M, Matsumoto M, Yano H, Taniguchi H and Nagayasu T: Evaluation of totally implantable central venous access devices with the cephalic vein cut-down approach: Usefulness of preoperative ultrasonography. J Surg Oncol 113(1): 114-119, 2016. PMID: 26645575. DOI: $10.1002 /$ jso.24100

10 Cavallaro G, Sanguinetti A, Iorio O, D'Ermo G, Polistena N, Avenia N, Silecchia G and De Toma G: Ultrasound-guided vein puncture versus surgical cut-down technique in totally implantable venous access devices (Tivads): A prospective comparative study on safety, efficacy and complications. Int Surg 99(4): 475-478, 2014. PMID: 25058787. DOI: 10.9738/INTSURG-D-14-00008.1

11 Jablon LK, Ugolini KR and Nahmias NC: Cephalic vein cut-down verses percutaneous access: a retrospective study of complications of implantable venous access devices. Am J Surg 192(1): 63-67, 2006. PMID: 16769277. DOI: 10.1016/j.amjsurg.2005.11.012

12 Chang HM, Hsieh CB, Hsieh HF, Chen TW, Chen CJ, Chan DC, Yu JC, Liu YC and Shen KL: An alternative technique for totally implantable central venous access devices. A retrospective study of 1311 cases. Eur J Surg Oncol 32(1): 90-93, 2006. PMID: 16289481. DOI: 10.1016/j.ejso.2005.09.004

13 Seiler CM, Frohlich BE, Dorsam UJ, Kienle P, Buchler MW and Knaebel HP: Surgical technique for totally implantable access ports (TIAP) needs improvement: a multivariate analysis of 400 
patients. J Surg Oncol 93(1): 24-29, 2006. PMID: 16353193. DOI: $10.1002 /$ jso. 20410

14 Matsushima $\mathrm{H}$, Adachi T, Iwata T, Hamada T, Moriuchi $\mathrm{H}$, Yamashita M, Kitajima T, Okubo $\mathrm{H}$ and Eguchi S: Analysis of the outcomes in central venous access port implantation performed by residents via the internal jugular vein and subclavian vein. J Surg Educ 74(3): 443-449, 2017. PMID: 27932306. DOI: 10.1016/j.jsurg.2016.11.005

15 Hashimoto S, Otsubo R, Adachi M, Doi R, Shibata K, Sano I, Shibata Y, Nakazaki T, Taniguchi H and Nagayasu T: Cephalic vein cut-down for totally implantable central venous access devices with preoperative ultrasonography by surgical residents. In Vivo 33(6): 2079-2085, 2019. PMID: 31662541. DOI: 10.21873/invivo. 11707

16 Schreckenbach T, Münch I, El Youzouri H, Bechstein WO and Habbe N: The safety level of total central venous access port implantation performed by residents. J Surg Educ 76(1): 182192, 2019. PMID: 30120065. DOI: 10.1016/j.jsurg.2018. 07.005
17 Hüttner FJ, Bruckner T, Hackbusch M, Weitz J, Bork U, Kotschenreuther P, Heupel O, Kümmel S, Schlitt HJ, Mattulat M, Pintér L, Seiler CM, Gutt CN, Nottberg HS, Pohl A, Ghanem F, Meyer T, Imdahl A, Neudecker J, Müller VA, Gehrig T, Reineke M, von Frankenberg M, Schumacher G, Hennes R, Mihaljevic AL, Rossion I, Klose C, Kieser M, Büchler MW, Diener MK and Knebel P: Primary open versus closed implantation strategy for totally implantable venous access ports: The Multicentre Randomized Controlled PORTAS-3 Trial (DRKS 00004900). Ann Surg 272(6): 950-960, 2019. PMID: 31800490. DOI: 10.1097/SLA.0000000000003705

18 Machat S, Eisenhuber E, Pfarl G, Stübler J, Koeblinger C, Zacherl J and Schima W: Complications of central venous port systems: a pictorial review. Insights Imaging 10(1): 86, 2019. PMID: 31463643. DOI: 10.1186/s13244-019-0770-2

Received December 29, 2020

Revised January 12, 2021 Accepted January 13, 2021 